\title{
Cortical development associated with conjugation of Paramecium
}

\author{
M. Rosario Romero and Antonio Torres \\ Departamento de Microbiologia, Facultad de Biologia, Universidad de Sevilla, Apdo. 1095. 41080 Sevilla, Spain
}

\section{SUMMARY}

The cortical cytoskeleton of Paramecium is characterized by a complex, polarized and asymmetrical organization. In order to analyse the cortical development of Paramecium tetraurelia during the sexual process of conjugation, different antibodies have been used to follow the development of five cortical components: basal bodies, ciliary rootlets, outer lattice, epiplasm and cytospindle. This study demonstrates that the cortex of Paramecium undergoes an elaborate development process following conjugation. Some of the cortical structures that are not renewed at any other moment of the cell cycle, are resorbed after conjugation and replaced by other newly formed ones. The reorganization of the cortical components occurs according to different morphogenetic waves that spread over the cell surface. The oral system and the preoral suture line act as morphogenetic epicentres.

Key words: Paramecium, conjugation, cortical morphogenesis

\section{INTRODUCTION}

The cortical pattern of Paramecium is characterized by its asymmetry. It displays dorsoventral and anteroposterior polarity at both whole cell and cortical unit levels. The anterior and posterior sutures and the oral apparatus define the ventral surface and determine the right and left sides of the cell.

The cortex of Paramecium consists of plasma membrane, alveolar system and epiplasm (a fibrous skeleton underlying the cortical membranes). It is molded into ridges which form a pattern of parallelograms over the cell surface. Each parallelogram delimits a cortical unit, the basic unit of the cortex. Cortical units are arranged in parallel longitudinal rows. Each cortical unit contains one or two basal bodies (1-bb and 2-bb units, respectively), its associated postciliary and transverse microtubular ribbons, one ciliary rootlet and one or two cilia. The arrangement of these elements within the cortical unit establishes an asymmetry that is fairly manifested by the ciliary rootlet, which arises from the basal body's anterior right quadrant and is directed anteriorly. The distribution of 1-bb and 2-bb units over the cell surface is regionalized (Sonneborn, 1975; Iftode et al., 1989). Thus, in the interphase cell, they delineate three different fields: the 2-bb field, where every unit contains two basal bodies, the 1-bb field, with one basal body per unit, and the mixed field, where randomly distributed 1-bb and 2-bb units coexist.

The chief developmental pathways in Paramecium are vegetative division and the sexual process (conjugation). These are the phases when morphogenetic events take place. During cell division, cell components must be duplicated in order to produce two complete daughter cells. Moreover, new microtubular structures are transiently required for the morphogenetic events to be properly carried out (cortical cytospindle, micronuclear mitotic spindle and macronuclear microtubules). Cortical morphogenesis throughout cell division in Paramecium has long been studied (Dippell, 1965, 1968; Kaneda and Hanson, 1974; Fernández-Galiano, 1978; Cohen et al., 1982; Iftode et al., 1989; Delgado et al., 1990). The interphase cortical pattern undergoes important modifications during vegetative reproduction. All of the cortical structures are reorganized along waves spreading from the oral region, the fission furrow acting as a secondary inductive zone. The responses of the different regions to the morphogenetic waves depend on their positions on the cell surface (Iftode et al., 1989).

During the sexual process of conjugation in Paramecium, as in other ciliates, cells of complementary mating types mutually activate and unite. In conjugating pairs, a series of nuclear events, including micronuclear meiosis, exchange of pronuclei and syngamy, and fragmentation of the macronucleus, occurs. When the cells separate, postzygotic nuclear divisions, differentiation of the new macroand micronuclei and resorption of the old macronucleus continue in the exconjugants. Moreover, during this process, the preexisting oral apparatus and other cortical structures are resorbed and rebuilt. As in division morphogenesis, transitory microtubular elements appear. Nuclear and stomatogenic events have been studied in detail (Grandchamp and Beisson, 1981; Ng and Mikami, 1981; $\mathrm{Ng}$ and Newman, 1984; Ng, 1986; Tam and Ng, 1986; Kwok and $\mathrm{Ng}$, 1989). However, the dynamics of cortical structures other than the oral apparatus in conjugation, has never been described.

In this study, we have followed the development of different cortical components in conjugation, by using a set of antibodies that recognize cytoskeletal structures. Our obser- 
vations indicate that conjugation is a process in which not only nuclei and the oral apparatus are renewed, but also the other cortical components undergo morphogenetic changes. This morphogenetic process includes regression and neoformation waves spreading over the whole cell surface and originating from the oral system and the anterior suture line.

\section{MATERIAL AND METHODS}

\section{Strains and growth conditions}

This study has been carried out on strain d4-2 of Paramecium tetraurelia, mating types VII and VIII. The cells were grown at $27^{\circ} \mathrm{C}$ according to the Sonneborn procedure (1970a) in Cerophyl medium bacterized the day before with Klebsiella pneumoniae and supplemented with $0.4 \mu \mathrm{g} / \mathrm{ml} \beta$-sitosterol.

\section{Sampling}

Postautogamous cells of complementary mating types were grown in tubes for three days and mildly starved to induce mating reactivity at $27^{\circ} \mathrm{C}$. The two mating types were mixed in Petri dishes, and about 1.5 hours after agglutination the cells were fed with medium to terminate conjugation of loose pairs and to prevent further formation of new pairs, so that synchronized samples could be obtained. About three hours after mixing, tight pairs were collected. About three hours later the pairs began to separate. Exconjugant cells were collected, permeabilized and fixed at different times, ranging from 5 to 45 minutes after separation.

\section{Immunofluorescence}

Exconjugant cells were permeabilized for 5 minutes in the microtubule stabilizing buffer PHEM (Schliwa and Van Blerkom, 1981) containing $1 \%$ Triton $\mathrm{X}-100$. Then cells were fixed in freshly prepared 2\% paraformaldehyde in PHEM buffer for 1 hour. After washing with Tris-buffered saline (TBS) or phosphate-buffered saline (PBS) containing $0.3 \%$ Tween 20 and 3\% bovine serum albumin (BSA), cells were incubated for 1-2 hours in the primary antibody diluted in the same washing solution. Then they were washed several times and incubated for 1 hour in the secondary antibody diluted 1:200 in the same buffer. After washing, cells were mounted in glycerol containing $2 \% \mathrm{~N}$-propyl gallate and observed under a Zeiss III epifluorescent microscope and photographed with Kodak Tri-X film. The same results were obtained using the same method without fixation. In this case, PHEM buffer was used throughout the process.

\section{Antibodies}

The primary antibodies used in this study, as well as the experimental conditions, sources and specificities, are shown in Table 1. The second antibodies were FITC-labelled goat anti-rabbit antibody, FITC-labelled anti-mouse Ig (Pasteur Production, Paris) or biotinylated sheep anti-mouse Ig, detected by Texas Red-labelled streptavidin (Amersham).

\section{RESULTS}

\section{Basal bodies}

The monoclonal antibody 1A2, anti-tyrosylated $\alpha$-tubulin was used as the main marker of basal bodies. In Parame cium visualized by immunofluorescence, this antibody only decorates basal bodies, part of the contractile vacuole rootlets and part of the postoral fibres. In interphase cells, immunofluorescence with anti-tyr reveals exactly the same pattern of basal body distribution as that deduced by Iftode et al. (1989) from silver-stained images (Fig. 1).

Our results show that the interphase pattern of basal bodies is altered during conjugation by resorption of one basal body in every unit of the 2-bb field. Furthermore, the right side of the oral vestibulum is disorganized because of the cell fusion and its basal bodies are later rearranged into rows in the exconjugant (Figs 3, 4A, 5A). In pairs at an advanced phase of conjugation, as well as in early exconjugants, every unit in the 2-bb field of the cortex has lost one basal body and so displays only a single basal body (Figs 2, 3, 38B). Basal body resorption continues in the exconjugant following an anteroposterior sequence on both the ventral and dorsal surfaces. This resorption wave spreads over the mixed field as well, where normally 1-bb and 2-bb units coexist. Most of the 2-bb units lose one of their basal bodies, so, as the resorption wave progresses, the mixed field is reduced and the zone with single basal bodies is increased. The dorsal surface (Figs 6-8) is the last region invaded by the resorption wave. At the end of this process, resorption of one basal body has occurred in every 2 bb unit.

Resorbed basal bodies are replaced by new ones that reconstruct the normal pattern of basal body distribution. When the resorption wave reaches the dorsal surface of the cell, basal body duplication has already begun on the ventral surface (Figs 4A, 7, 38B). Basal body duplication begins at the basal body rows closest to the buccal opening. This duplication process rapidly propagates to the adjacent rows on both the right and left. Duplication starts from the anterior suture line and progresses posteriorly along each row of basal bodies (Fig. 9), adding one basal body in the units that normally display two basal bodies in a mature vegetative cell (Fig. 5A,B).

During basal body duplication in exconjugant Parame cium, the anterior and the posterior basal bodies of a cortical unit show different reactivities towards some antitubulin antibodies, the anterior one being the most strongly decorated by universal anti-tubulin antibodies such as anti$\beta$-tubulin (data not shown) and by the monoclonal antibody 1A2 against $\alpha$-tyr tubulin (Fig. 4B). However, the posterior basal body, faintly decorated by these antibodies, is

Table 1. Antibodies used in this study

\begin{tabular}{llll}
\hline Antibody & \multicolumn{1}{c}{ Specificity } & References & Dilution \\
\hline Anti-kd & Ciliary rootlet & Sperling, 1991 & $1 / 500$ \\
$\mathrm{I}_{4} \mathrm{~B}_{7}$ & Epiplasm & Adoutte, Clerot & PBS \\
$\mathrm{I}_{3} \mathrm{D}_{3}$ & Outer lattice & Adoutte, Clerot & PBS \\
$1 \mathrm{~A}_{2}$ & Tyrosinylated $\alpha$-tubulin & Kreis, 1987 & $1 / 5$ \\
6-11B-1 & Acetylated $\alpha$-tubulin & Piperno, 1985 & $1 / 5$ \\
MPM-2 & Mitotic phosphoproteins & Davis, 1983 & $1 / 5$ \\
Anti- $\beta$-tubulin & $\beta$-tubulin & Amersham & PBS \\
\hline
\end{tabular}



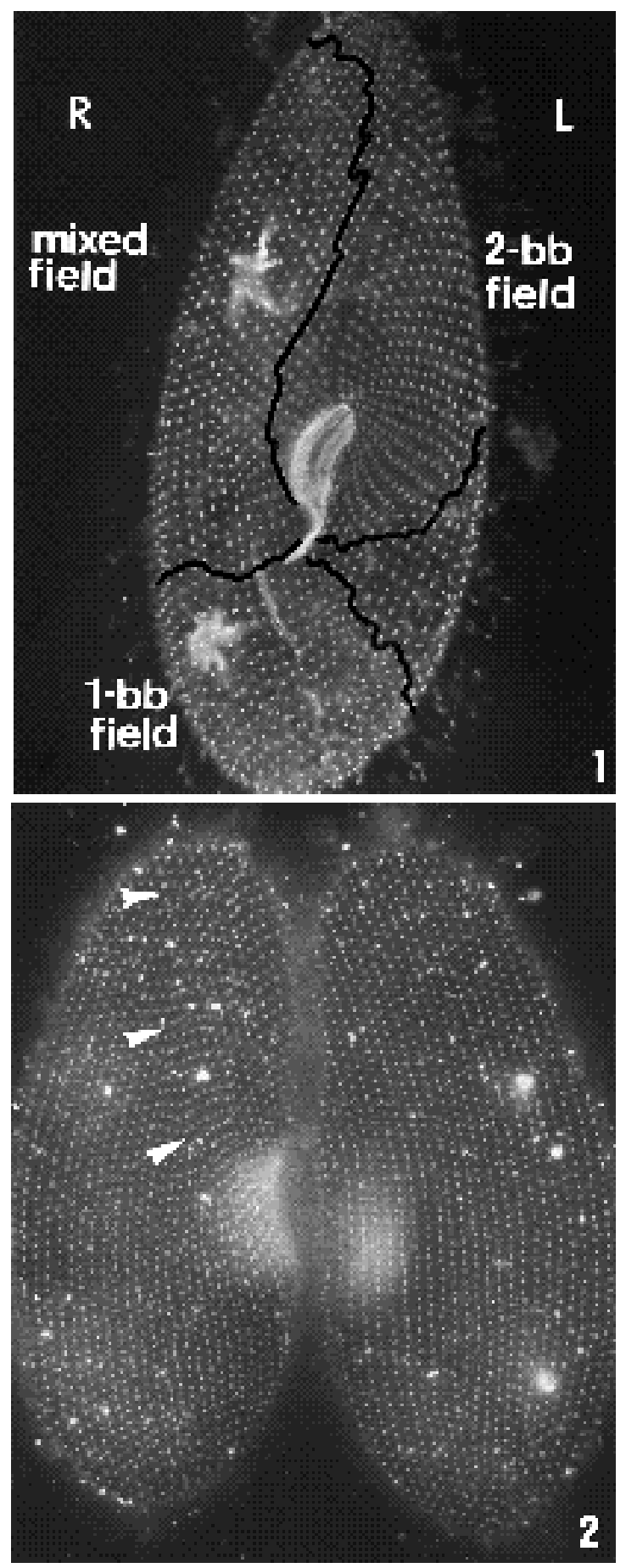

Fig. 1. Immunofluorescence image of an interphase Paramecium (ventral surface) labelled with the antibody 1A2. This antibody reveals the pattern of basal body distribution over the cell surface. Black lines delimit the three different fields existing in interphase: the 1-bb field, in which every cortical unit contains a single basal body, the 2-bb field, where every unit contains two basal bodies and the mixed field, where 1-bb and 2-bb units coexist. R, right side of the cell; $\mathrm{L}$, left side. $\times 650$.

Fig. 2. Immunofluorescence image of a late conjugating pair decorated by the antibody $1 \mathrm{~A} 2$. One basal body of each cortical unit in the 2-bb field has been resorbed (arrowheads). $\times 800$. more strongly stained with anti-PA tubulin than the anterior one (data not shown). These basal body staining patterns observed in exconjugants during basal body duplication exactly coincide with those seen during basal body proliferation in division (Adoutte et al., 1991; our unpublished observations).

\section{Cytospindle}

The cytospindle is a transitory cortical structure consisting of bundles of 4 to 20 longitudinal microtubules that run from pole to pole on the right side of the ciliary rows, at the top of the longitudinal ridges of the cortex (Kaneda and Hanson, 1974; Sundararaman and Hanson, 1976; Cohen et al., 1982). This microtubular array appears on the cell cortex during division and sexual processes.

Cytospindle assembly in exconjugant cells (Fig. 38A) begins about 5 minutes after pair separation. At this time micronuclei are in metaphase and fragments of the old macronucleus are observed in the cytoplasm (Fig. 13). The first microtubular bundles of the cytospindle appear around the oral cavity, initially on the right side (Fig. 10) and then on the left (Fig. 11). The cytospindle bundles gradually increase their length and thickness. Longitudinal growth occurs at both ends of the bundles, until they reach the anterior and posterior suture lines (Figs 11, 12,16). At the same time, new microtubular bundles appear, adjacent to the preexisting ones, following a transverse sequence which starts from the oral opening and spreads to the right and left towards the dorsal surface of the cell (Figs 14, 15). In this manner, every longitudinal ridge running between rows becomes occupied by a microtubular bundle (Figs 16, 17). Cytospindle assembly is completed by bidirectional elongation of all the bundles, which first reach the anterior pole and then the posterior pole of the cell.

The process of cytospindle formation takes about 10-15 minutes. During this time, micronuclear mitosis continues and, when the cytospindle is completed, micronuclei are in telophase. Resorption of old macronuclear fragments progresses during this time as well. At late phases of cytospindle assembly most of the fragments of the old macronucleus have been resorbed. The cytoplasmic microtubular network at this phase has fewer microtubules than normal (Fig. 18).

When the cytospindle reaches the posterior end of the cell it immediately begins to disassemble (Figs 19-23, 38A). The regression of each microtubular bundle starts from the anterior and posterior suture lines, i.e. bundles shorten from both ends until they disappear. The bundles closest to the oral apparatus are the first ones to be disassembled (Fig. 19). The cytospindle disassembly wave progresses from the buccal opening to the right and left sides of the cell, this progression being faster on the left side. Moreover, the shrinkage of the microtubular bundles is faster at the posterior extreme than at the anterior one. The left ventral surface is the first zone to lose the cytospindle (Fig. 20), followed by the right ventral surface. At later stages of the disassembly process, short bundles of microtubules, shrunk at their extremes, remain on the dorsal anterior surface of the exconjugant cell (Fig. 21).

In exconjugant paramecia, cytospindle assembly and development of the new oral apparatus overlap. As conju- 

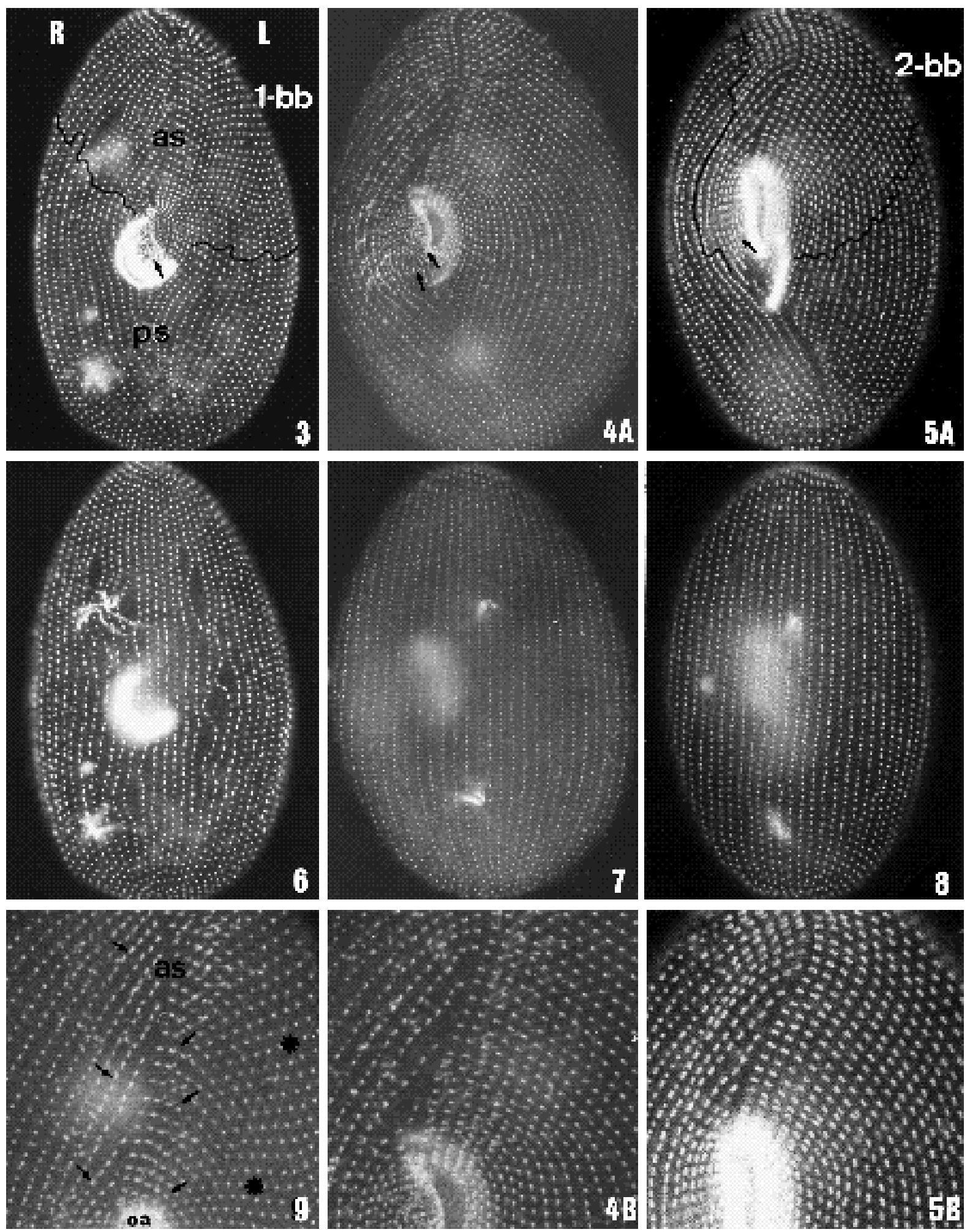

gating cells separate, the new oral apparatus is poorly developed. It is small and C-shaped (stage 4, $\mathrm{Ng}$ and Newman, 1984; Figs 3, 10). When the cytospindle has formed, lying along the entire cell, the oral apparatus has attained its mature pattern (stage 6, Ng and Newman, 1984), but it still lacks the postoral fibres that were also disassembled during conjugation (Fig. 18). The postoral fibres grow while the cytospindle regresses. Thus, at the end of the disassembly process the postoral fibres have attained their normal length (Fig. 24). At this stage (stage 8, Ng and Newman, 1984) exconjugating cells recover their ability to feed.

\section{Ciliary rootlets}

Ciliary rootlets (kinetodesmal fibres) are striated fibrils aris- 
Figs 3-9. Immunofluorescence images of exconjugants labelled by the antibody $1 \mathrm{~A} 2$, showing the reorganization of the basal body pattern.

Fig. 3. At an early stage, the anterior region of the cell (outlined zone) displays a single basal body in each cortical unit. The 2-bb field and part of the mixed field have been affected by the basal body resorption wave. The pattern of basal bodies to the right of the oral apparatus is disorganized (arrow). as, anterior suture; ps, posterior suture. $\times 875$.

Fig. 4. A later stage, when basal body duplication is taking place. (A) View of the entire cell. Basal bodies to the right of the oral apparatus are still disorganized (arrows). $\times 875$. (B) Enlargement of a portion of the anterior region of this cell. Basal bodies have just been duplicated. The anterior basal body of each 2-bb unit appears more strongly stained by the antibody $1 \mathrm{~A} 2$ than the posterior one. $\times 1600$.

Fig. 5. A later stage of basal body duplication. (A) View of the entire cell. Basal bodies on the right of the oral apparatus have been arranged in rows. The ventral surface of the exconjugant has recovered the normal pattern of basal bodies. $\times 875$.

(B) Enlargement of the anterior region of the cell in A. The two basal bodies of each unit show the same reactivity towards the antibody. $\times 1600$.

Figs 6-8. Dorsal views of the cells in Figs 3, 4 and 5, respectively. $\times 875$.

Fig. 6. The basal body resorption wave has only affected the anterior pole, which contains $1-b b$ per unit. The equatorial region still displays 1-bb and 2-bb units randomly distributed.

Fig. 7. Most of the 2-bb units on the dorsal surface have resorbed one basal body.

Fig. 8. Basal bodies in the anterior pole have been duplicated, but on the rest of the dorsal surface most of the units still contain one single basal body.

Fig. 9. A portion of the anterior region of an exconjugant cell showing the beginning of the basal body duplication wave. The units closest to the anterior suture line (as) in every basal body row already contain two basal bodies (arrows), whereas the more posterior units of each row still display one single basal body (asterisks). oa, oral apparatus. $\times 1600$.

ing from the basal bodies (in cortical units with two basal bodies it arises from the posterior one). They run straight anteriorly, close to the right side of the basal body row. They extend for a distance of several cortical units, overlapping others in the same longitudinal row. The overlapping fibres constitute longitudinal bundles running the full length of the cell (Dippell, 1964).

Ciliary rootlets have been visualized by means of immunofluorescence with the anti-kd antiserum. In conjugation of Paramecium, the first modification of the ciliary rootlet pattern is observed when cells separate. As mentioned above, the right vestibulum is disorganized in the new exconjugants, with disorganized basal bodies, which lack ciliary rootlets (Fig. 25A,B, 38C). At this stage, ciliary rootlets on the rest of the cortex have not been modified yet. They are still long fibres constituting longitudinal bundles (Fig. 25A). As the basal bodies on the right vestibulum are being arranged in rows, small fibres start growing from them (Figs 26A,B, 27A,B).

Our observations of immunofluorescence with the anti-kd antiserum indicate that ciliary rootlets are renewed over the entire cortex (Fig. 38C): the old fibres regress and new ones replace them. First, old fibres undergo a partial regression, becoming shorter and thinner. Soon they detach from their basal bodies, to be completely disassembled in the internal cytoplasm. A new ciliary rootlet then develops in every unit to replace the old ones (Figs 26B, 27B). Detached old fibres accumulate in the cytoplasm and are clearly visualized by immunofluorescence with the anti-kd antibody. Anti-kd decoration inside the cell changes throughout the ciliary rootlet remodelling process. At an early stage, as in interphase cells, this antibody does not recognize any structure within the cytoplasm (Fig. 28). However, when some of the cortical units have lost their old ciliary rootlets, many scattered fibrils are seen in the cytoplasm (Fig. 29). Later, as new ciliary rootlets grow, the number of inner fibrils decreases until eventually they disappear.

As mentioned above, the new exconjugant cells keep their old ciliary rootlets over the entire cortex, except on the right side of the oral apparatus. At this time, a wave of regression and posterior detachment of the old fibres begins. This wave commences in the basal body rows closest to the oral opening (Fig. 25B), from where it extends to the adjacent rows on the right and left, until it reaches the dorsal surface. Within each row, it starts from the anterior suture line and progress posteriorly. Thus, the first fibres to shorten are the ones closest to the preoral suture, which no longer extend across it (Fig. 26B). Then, the remodelling wave extends posteriorly along the rows, more quickly on the left side than on the right (Fig. 27A). At the end of this process all ciliary rootlets of the exconjugant will have been replaced (Figs 30, 31).

Sperling et al. (1991) reported that the decoration of ciliary rootlets with the monoclonal antibody MPM-2, specific for phosphoproteins, just precedes fibre disassembly. They also observed MPM-2 staining in exconjugant cells. In order to find out whether this staining is correlated with ciliary rootlet reorganization (as it occurs during division), immunofluorescence with MPM-2 was performed on exconjugant cells (Figs 32, 33). We observed that MPM-2 staining in exconjugant Paramecium starts in the basal body rows closest to the oral apparatus and proceeds in an anteroposterior wave originating from the anterior suture line within each row. It precedes fibre disassembly and follows exactly the spatial sequence observed for ciliary rootlet remodelling.

\section{Outer lattice and epiplasm}

Cortical units in Paramecium are delineated by meshes that constitute a regular cortical network, the outer lattice (Von Gelei, 1937; Parducz, 1962; Ehret and MacArdle, 1974; Cohen el al., 1987). Underlying the cortical membranes there is a fibrous layer, the epiplasm. The epiplasm is organized as individual scales within each cortical unit, i.e. within each mesh of the outer lattice. Epiplasm and outer lattice development are therefore strictly coordinated (Fig. 38D).

When cells separate following conjugation, the basal body rows surrounding the oral cavity are disorganized and cortical units in this region are not well defined, especially on the right side of the oral apparatus. I3D3 and I4B7 decoration in this area of the cortex is very faint in early exconjugants (Figs 34, 35). During conjugation the cells become shorter, so that the outer lattice meshes in the exconjugant are smaller than in interphase cells. 

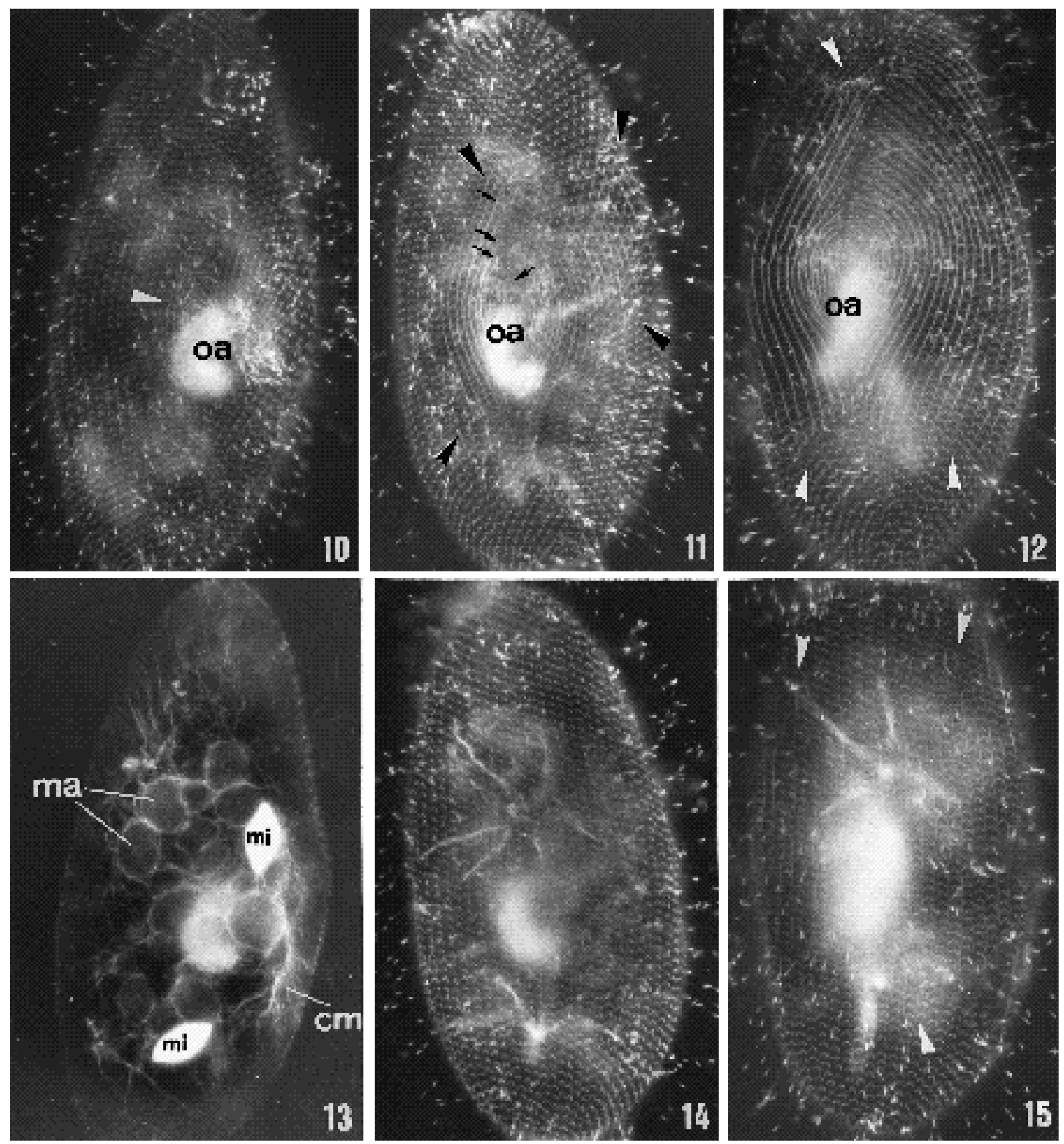

Figs 10-15. Immunofluorescence images of three exconjugants at sucessive stages of cytospindle formation. Figs 10, 11, 12, 14 and 15 show 6-11B-1 decoration. oa, oral apparatus. $\times 980$.

Fig. 10. Initial stage of cytospindle assembly. The first microtubular bundles appear on the right side of the oral apparatus (arrowhead). Fig. 11. A later stage. Cytospindle bundles can be seen on the right and left (arrowheads). They are growing in thickness and length. The microtubular bundles closest to the oral apparatus are thicker and they have reached the anterior suture line (arrows).

Fig. 12. A more advanced stage of cytospindle formation. New microtubule bundles have been formed and the preexisting ones have grown (arrowheads). Many of them have reached the anterior suture, but still not the posterior one.

Fig. 13. Interior view of the cell in Fig. 10, decorated by anti- $\beta$-tubulin antibody. Fragments of the old macronucleus remain in the cytoplasm (ma). The micronuclei (mi) are in the 2 nd postzygotic metaphase. Many cytoplasmic microtubules (cm) are observed into the cell.

Fig. 14. Dorsal surface of the cell in Fig. 11. Cytospindle assembly wave has not invaded the dorsal surface yet.

Fig. 15. Dorsal surface of the cell in Fig. 12. Microtubular bundles have appeared on the dorsal surface of the exconjugant (arrowheads).

Our results with the monoclonal anti-outer lattice antibody, I3D3, indicate that, after conjugation, this structure is at least partially reorganized. A progressive appearance of new transverse partitions within some of the preexisting cortical units is observed in exconjugants (Figs 36, 37). These partitions always appear close to the anterior boundary of 

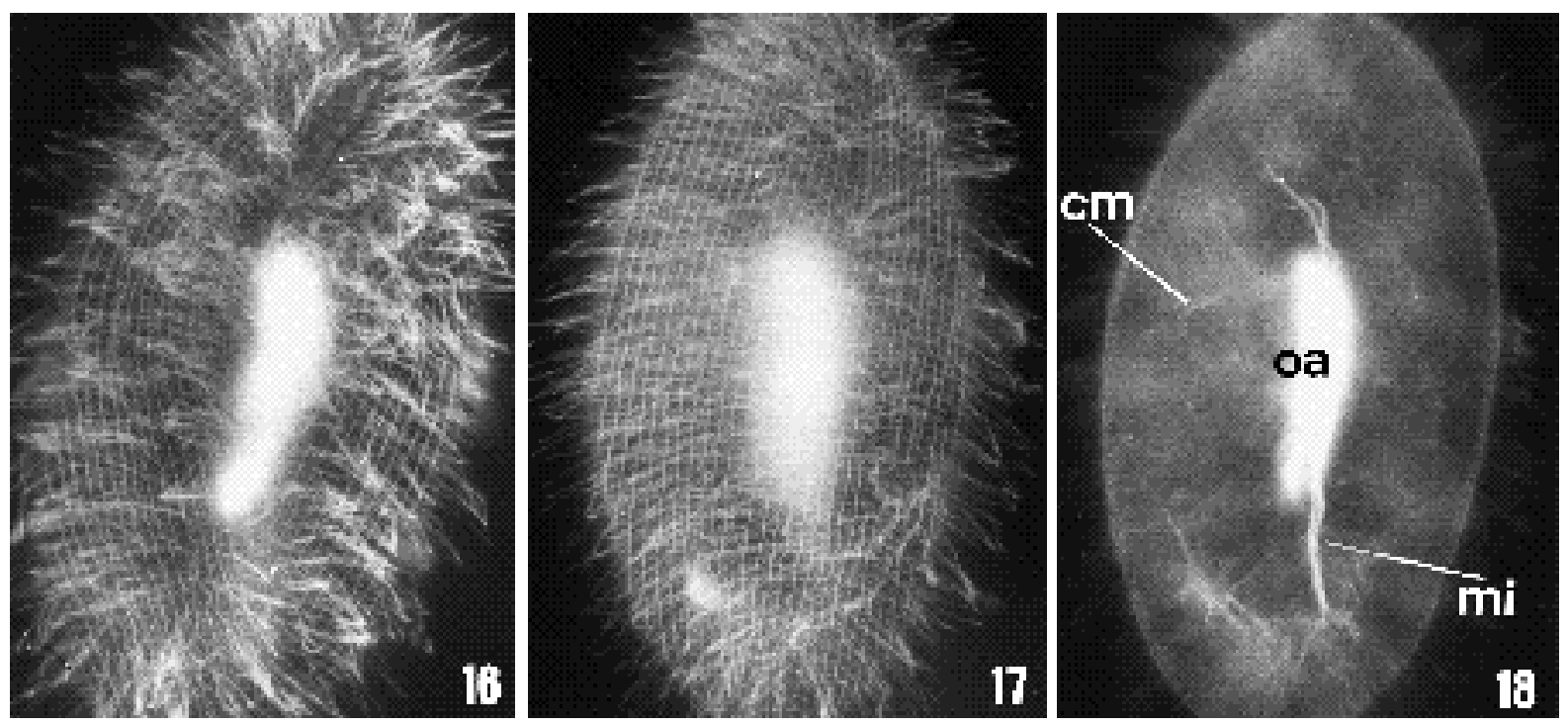

Figs 16-18. Exconjugant cell with a complete cytospindle, decorated by anti- $\beta$-tubulin antibody. $\times 875$.

Fig. 16. Ventral surface. The cytospindle bundles run all along the basal body rows from the anterior to the posterior sutures.

Fig. 17. Dorsal surface. Every longitudinal ridge at this stage is occupied by a microtubular bundle running from pole to pole of the cell.

Fig. 18. Interior view of the cell. The oral apparatus (oa) has attained its mature pattern, but the postoral fibres has not been formed yet. At this stage, the cell has fewer cytoplasmic microtubules $(\mathrm{cm})$. Micronuclei are in telophase. Long micronuclear mitotic spindles are observed (mi).

the unit. Formation of transverse partitions first occurs in the rows closest to the oral apparatus, and then extends to the dorsal surface. As newly formed transverse septa appear, degradation of some of the old ones takes place (Fig. 37), so that the number of cortical units is maintained. Thus, the position of transverse partitions of the outer lattice changes and they now define different units, mixing material coming from old adjacent units. Likewise, new septa separate the material of an old unit into two new ones.

This phenomenon of cortical unit reorganization is only observed in the mixed field of the cortex. Outer lattice meshes in 2-bb and 1-bb fields remain unaltered.

\section{DISCUSSION}

In this paper we describe the morphogenetic events occurring in the cortex of Paramecium during conjugation. The major cytoskeletal structures have been studied by means of immunological probes.

The morphogenetic strategy used by Paramecium to reproduce its oral and somatic basal body arrays during cell division is significantly different from other evolutionally distant ciliates. Whereas some ciliates such as Oxytrichids resorb and reorganize most of their basal bodies at every division, Paramecium conserves all basal bodies, and the new ones are arranged following the preexisting pattern (Sonneborn, 1963; Beisson and Sonneborn, 1965). Likewise, while most other ciliates develop their new oral apparatus independently of the old one and can regenerate it, Paramecium develops its new oral apparatus close to the old one during division and normally cannot regenerate it (Tartar, 1954; Sonneborn, 1963). The sexual processes of autogamy and conjugation therefore are the only occasions in the cell cycle when Paramecium renews its oral system. Our observations indicate that conjugation is also the morphogenetic process by which other cortical elements, conserved during division, undergo a remodelling process.

The development of the basal body pattern in conjugating cells has been followed mostly by using the monoclonal antibody $1 \mathrm{~A} 2$ as a basal body marker. The results obtained with this antibody were confirmed by using other anti-tubulin antibodies, such as anti- $\alpha$ - and anti- $\beta$-tubulin, 6-11B-1 and anti-axonemal tubulin of Paramecium (Cohen et al., 1982).

Basal body resorption occurs in cortical units containing two basal bodies. The question arises as to whether the anterior or the posterior basal body is the one disappearing. Immunofluorescence images lead us to think that the anterior basal body is the one resorbed while the posterior one remains. When stained with anti-tubulin antibodies, early exconjugant cells display, in every unit, only the fibrils normally associated with the posterior basal body, i.e. transverse and postciliary ribbons and ciliary rootlets.

During basal body duplication, the anterior and posterior basal bodies show different reactivities towards anti-tubulin antibodies. Since duplicating basal bodies in exconjugant cells show the same staining pattern seen in dividing cells (see results), it may be concluded that new basal bodies in exconjugant Paramecium, as in dividers (Dippel, 1968), appear anterior to the old ones.

Remodelling of transverse partitions of the outer lattice implies a modification of the preexisting cortical units. New transverse segments are formed and the epiplasmic material underlying each unit is redistributed into new units. Changes in the outer lattice meshes only occurs in the mixed field of the cortex, where 1-bb and 2-bb units appear randomly distributed. Moreover, new transverse partitions 

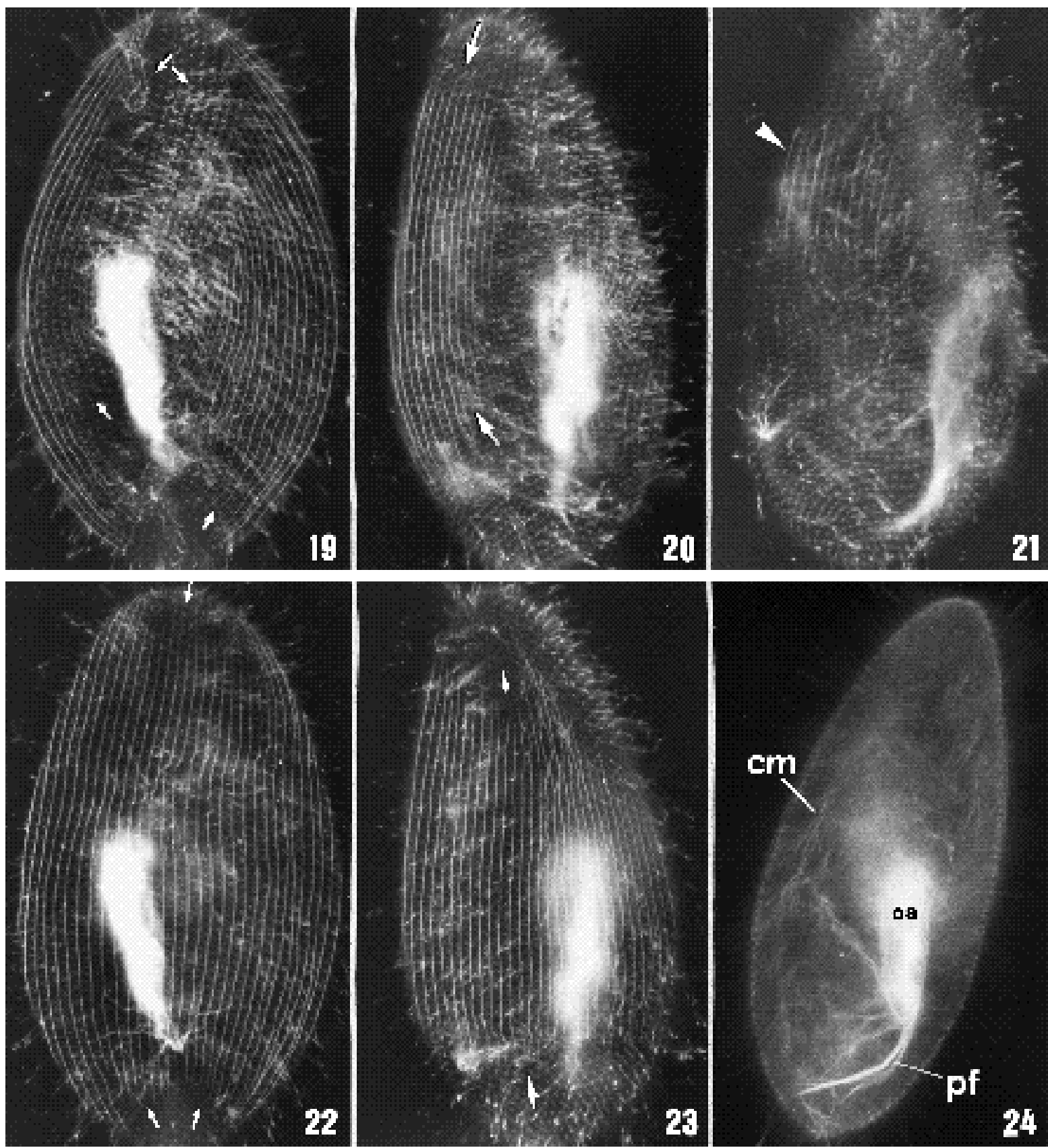

Figs 19-24. Exconjugant cells at different stages of cytospindle disassembly. All images are from 6-11B-1 decoration, except Fig. 24 which shows anti- $\beta$-tubulin staining.

Fig. 19. An early stage. Ventral surface. Microtubular bundles have begun to shorten from the suture lines (arrows), those closest to the oral apparatus being the ones more disassembled. $\times 900$.

Fig. 20. A later stage. Ventral surface. The wave of disassembly progresses (arrows). Microtubular bundles on the right side of the cell have already been resorbed. $\times 900$.

Fig. 21. At the last stages of cytospindle disassembly short fragments of microtubule bundles remain on the anterior dorsal surface (arrowhead). $\times 875$.

Fig. 22. Dorsal surface of the cell in Fig. 19. The wave of disassembly is beginning to invade the dorsal surface from both poles of the cell (arrows). $\times 900$.

Fig. 23. Dorsal view of the cell in Fig. 20. Microtubular bundles disassembly progresses from the anterior and posterior poles (arrows). $\times 900$.

Fig. 24. Interior view of a cell at a stage corresponding to that of Fig. 21 , decorated by anti- $\beta$-tubulin antibody. The postoral fibres (pf) have grown and the cytoplasmic network is recovering its normal number of microtubules $(\mathrm{cm}) . \times 825$. 

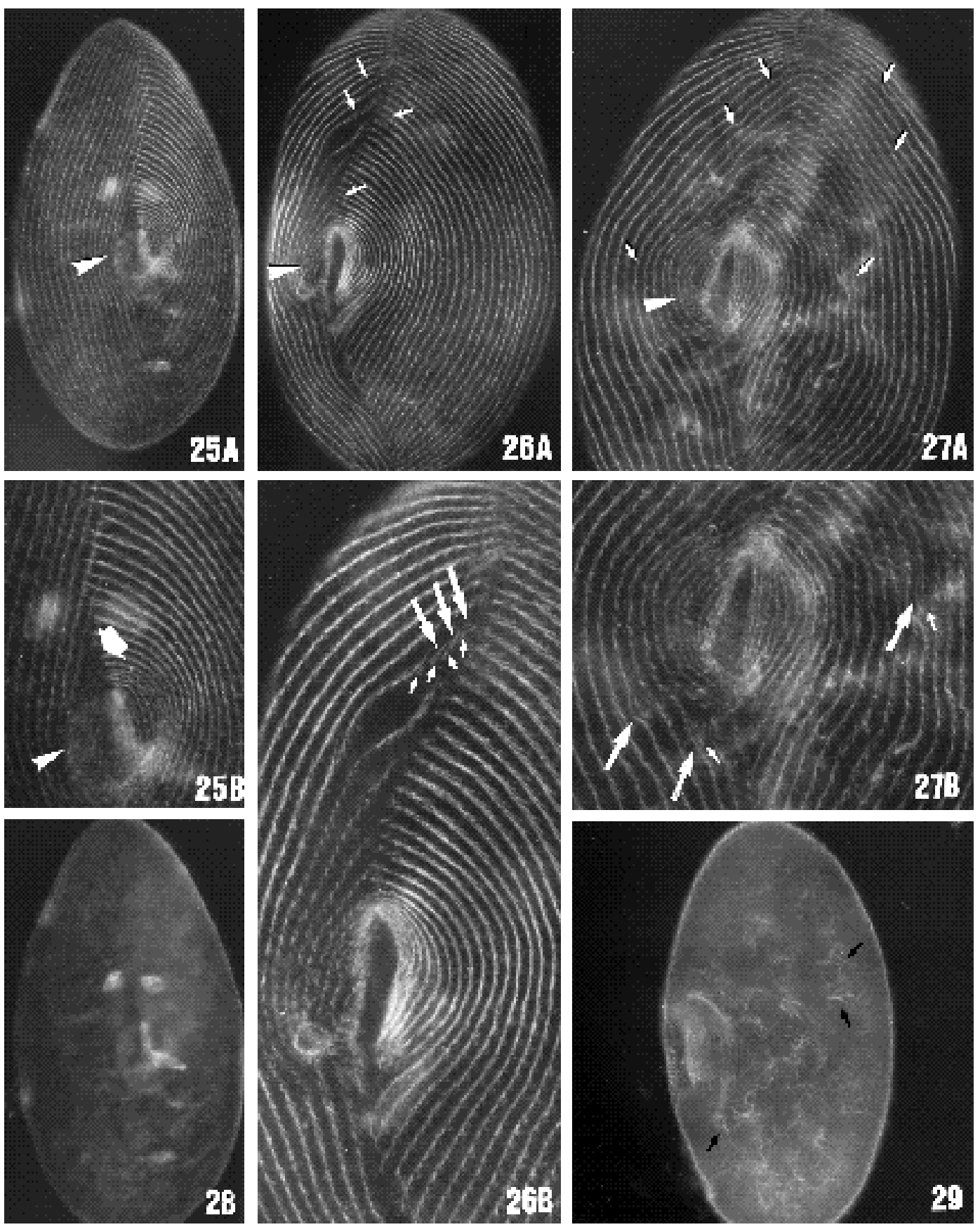

Figs 25-29. Immunofluorescence images of exconjugants decorated by the anti-kd antiserum.

Fig. 25. Early exconjugant. The zone on the right of the oral cavity (arrowhead) lacks ciliary rootlets, while the rest of the cortex keeps the old fibres. (A) View of the whole cell. $\times 765$. (B) Enlargement of a region of the cell showing the oral cavity and part of the anterior suture. The most anterior ciliary rootlets of the basal body rows closest to the oral apparatus have begun to shorten (arrow). $\times 1500$. Fig. 26. (A) The wave of ciliary rootlet remodelling extends to the adjacent basal body rows on the right and left, starting from the anterior suture line (arrows). As the basal bodies on the right of the oral opening are being arranged in rows, small ciliary rootlets start growing from them (arrowhead). $\times 875$. (B) Enlargement of part of the cell in Fig. 26A. The large arrows mark partially disassembled old fibres, detached from their anchoring points. The small arrows mark small new fibres which will replace the old ones. $\times 1870$.

Fig. 27. A later stage of the ciliary rootlet remodelling. The remodelling wave has spread posteriorly from the anterior suture line over the zone delimited by the arrows. On the rest of the cortex the old fibres still remain. (A) $\times 1000$. (B) Enlargement of the central region of the same cell. Large arrows mark old detaching ciliary rootlets; small arrows mark new developing fibres. $\times 1375$.

Fig. 28. Interior view of the early exconjugant of Fig. 25. The anti-kd antiserum does not recognize any fibrilar structure in the internal cytoplasm.

Fig. 29. Interior view of an exconjugant at an intermediate stage of the ciliary rootlet reorganization. Many scattered fibrils are recognized by the antiserum in the internal cytoplasm (arrows). They presumably correspond to old fibres detached from their basal bodies (compare to the image of Fig. 28). 

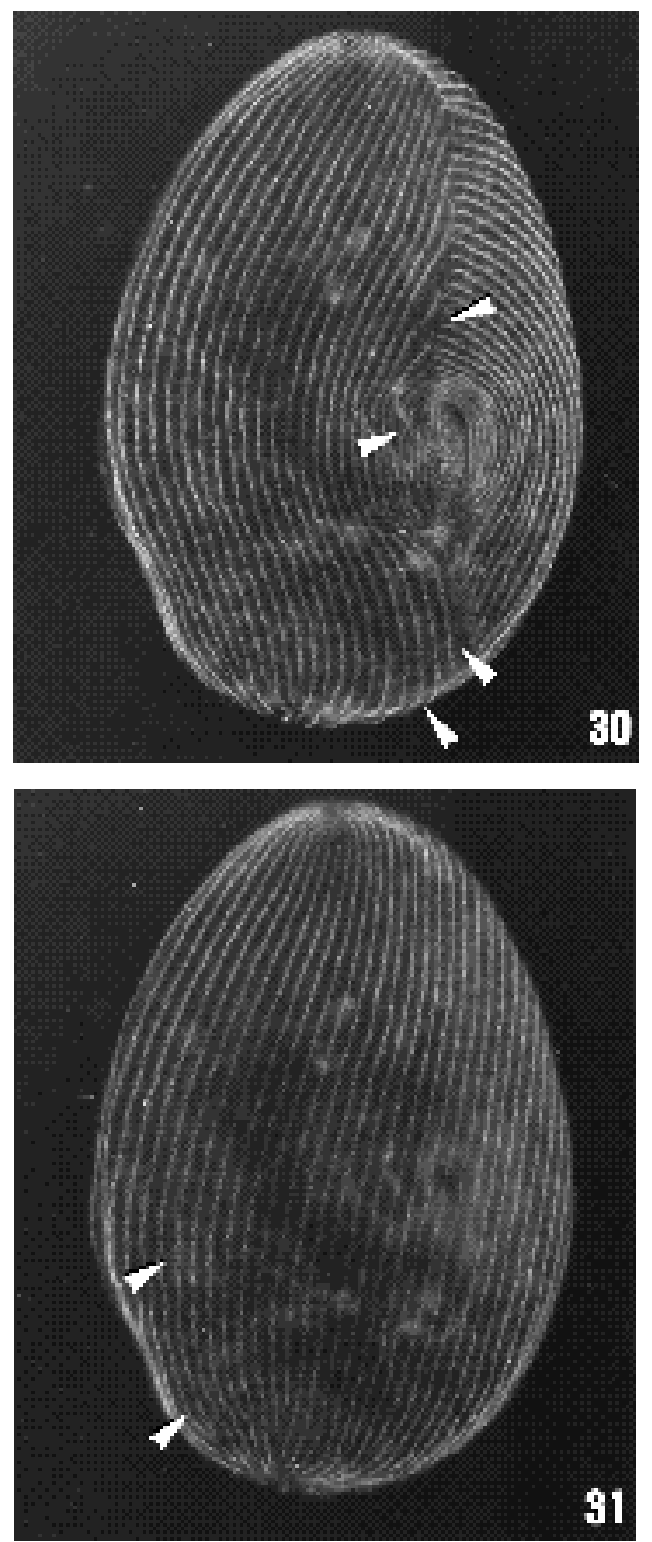

Figs 30, 31. Ventral and dorsal surfaces, respectively, of immunofluorescence images of an exconjugant Paramecium at an advanced stage of ciliary rootlet reorganization, when the remodelling wave has invaded the entire cell surface. All ciliary rootlets are new, but they have not attained their normal length yet (arrowheads). $\times 875$.

do not appear in every unit, only in some of them, without any apparent order in the basal body rows. It has been suggested that during division, basal body duplication and separation are needed for normal partitioning of the outer lattice meshes (Cohen et al., 1987). Therefore, it would be possible for new transverse segments to be formed within units where the basal body has been duplicated, between new and old basal bodies. That would mean that there would be a change of 1-bb and 2-bb unit distribution along the rows.

Ciliary rootlets are renewed after conjugation over the entire cortex. Our observations indicate that old ciliary rootlets are first partly disassembled, then detached from
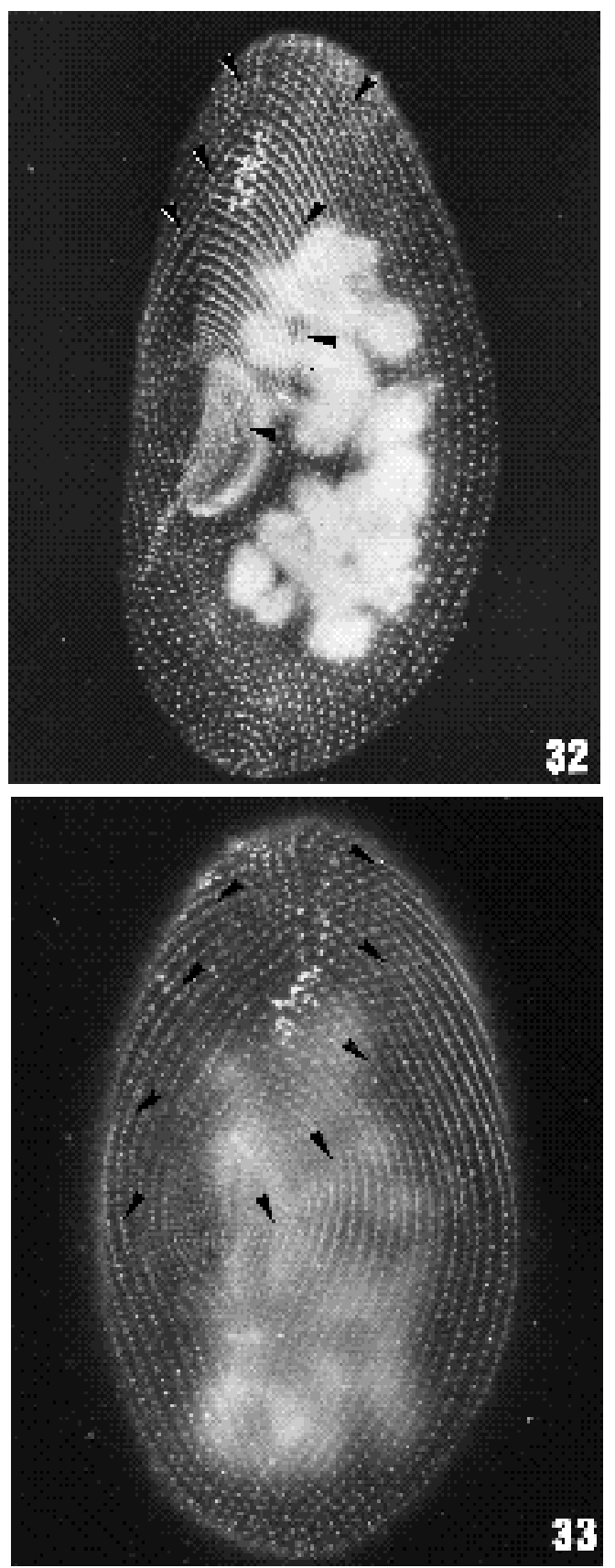

Figs 32, 33. Immunofluorescence images of two exconjugants at sucessive stages, labelled by the antibody MPM-2. $\times 975$.

Fig. 32. At an early stage, corresponding to that of the Fig. 25A, the ciliary rootlets closest to the anterior suture, which will be the first ones to disassemble, have been phosphorylated. Thus, they can be visualized by the MPM-2 antibody (arrowheads). The inner structures strongly stained are the macronuclear fragments.

Fig. 33. At a later stage, the wave of ciliary rootlet fibre phosphorylation has propagated posteriorly along the basal body rows, as well as transversely to right and left of the oral apparatus towards the dorsal surface of the cell (arrowheads).

their basal bodies and finally are completely disassembled in the internal cell cytoplasm. The evidence suggesting that the old fibres complete their disassembly in the cytoplasm comes from the immunofluorescence images obtained with 

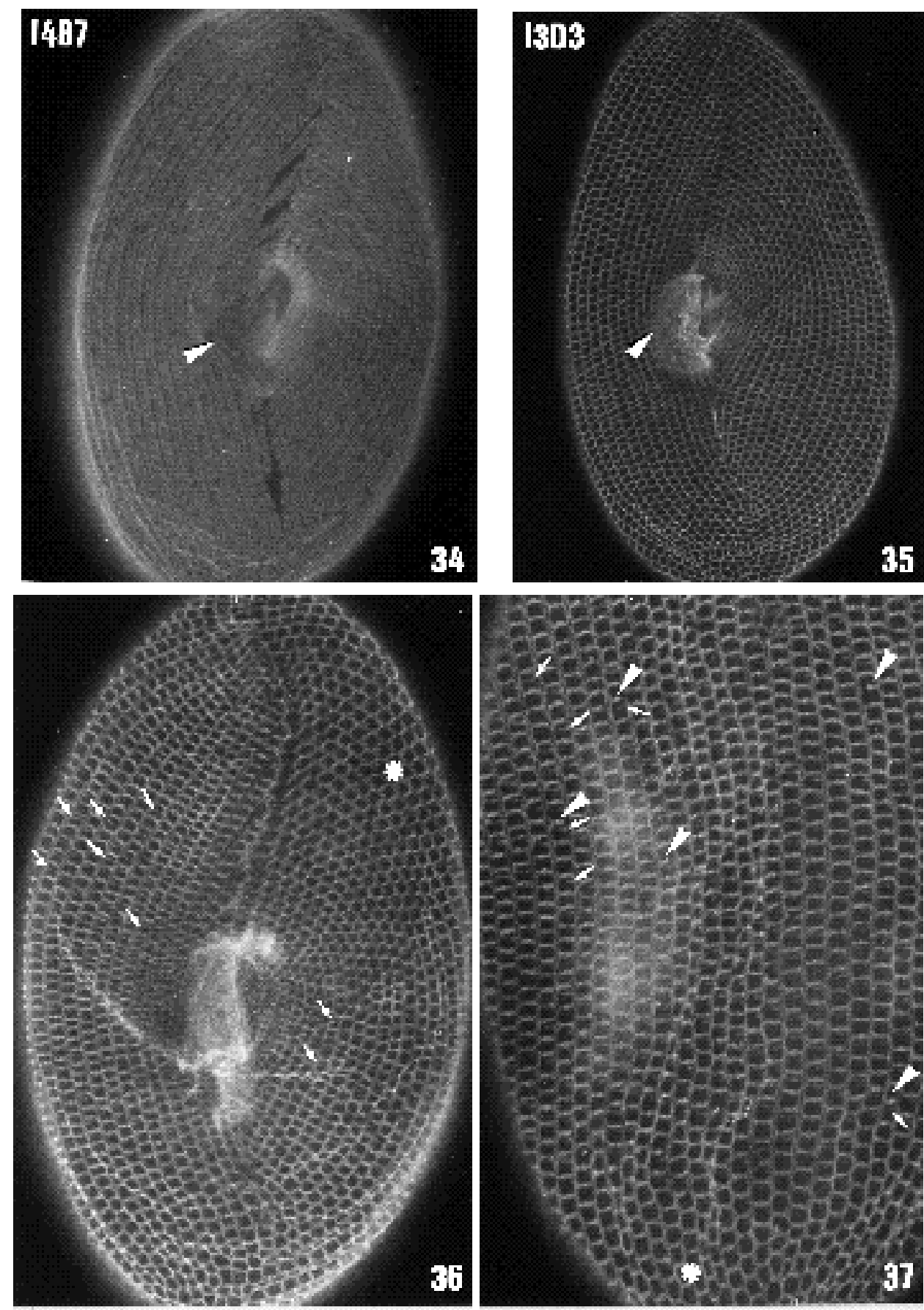

Fig. 34. Early exconjugant labelled by the anti-epiplasm antibody I4B7. The arrowhead marks the disorganized region on the right of the oral apparatus. $\times 1000$.

Figs 35-37. Exconjugant cells decorated by the anti-outer-lattice antibody I3D3.

Fig. 35. Early stage. Cortical units on the right side of the oral apparatus are not well defined (arrowhead). On the rest of the cortex the only modification of the cortical units has been the reduction of their size.

Fig. 36. At a later stage, formation of new transverse partitions within the preexisting meshes of the outer lattice is observed (arrows). They begin to appear on the right ventral side of the cell; therefore this cell displays more new partitions on the right side than on the left. The 2-bb field (asterisk) is not affected by this wave of remodelling of the outer lattice. $\times 1225$.

Fig. 37. A portion of the dorsal surface of an exconjugant at a stage following that of the cell in Fig. 36. The wave of outer lattice remodelling has invaded the dorsal surface of the exconjugant. As on the ventral surface, this remodelling only affects the mixed field. The 1-bb field (asterisk) and the 2-bb field remain unaltered. Moreover, not all the units in the mixed field undergo a new partition. As new septa are being formed (arrows), resorption of some of the old ones occurs (arrowheads). anti-kd antiserum on exconjugants and interphase cells. The old fibre might be detached by breakage at the proximal end leaving a fragment from which the new fibre would grow. Another possibility is that the new fibre pushing from the basal body displaces the old ciliary rootlets.

In Paramecium, reorganization of the ciliary rootlets during division has been studied in detail (FernándezGaliano, 1978; Iftode et al., 1989; Sperling et al., 1991). Old ciliary rootlets have been reported to become thinner and detach from their basal bodies, as we have observed in exconjugant cells. We examined dividing cells and obtained the same cytoplasmic decoration with the anti-kd antibody as in exconjugants. Such cells displayed many scattered fibres in the cytoplasm during ciliary rootlet remodelling. Sperling et al. (1991) analyzed ciliary rootlet reorganization in division at the cellular and molecular levels. They concluded that these fibres are composed of phosphoproteins whose hyperphosphorylation at cell division is probably responsible for the disassembly of the structure. We have also observed, by MPM-2 staining, that a phosphorylation wave just precedes the ciliary rootlet regression wave in exconjugants.

Cortical morphogenesis in conjugation, as in division, includes the appearance of a transient microtubular system, the cytospindle, thought to play a scaffolding role (Sundararaman and Hanson, 1976; Cohen et al., 1982; Iftode et 

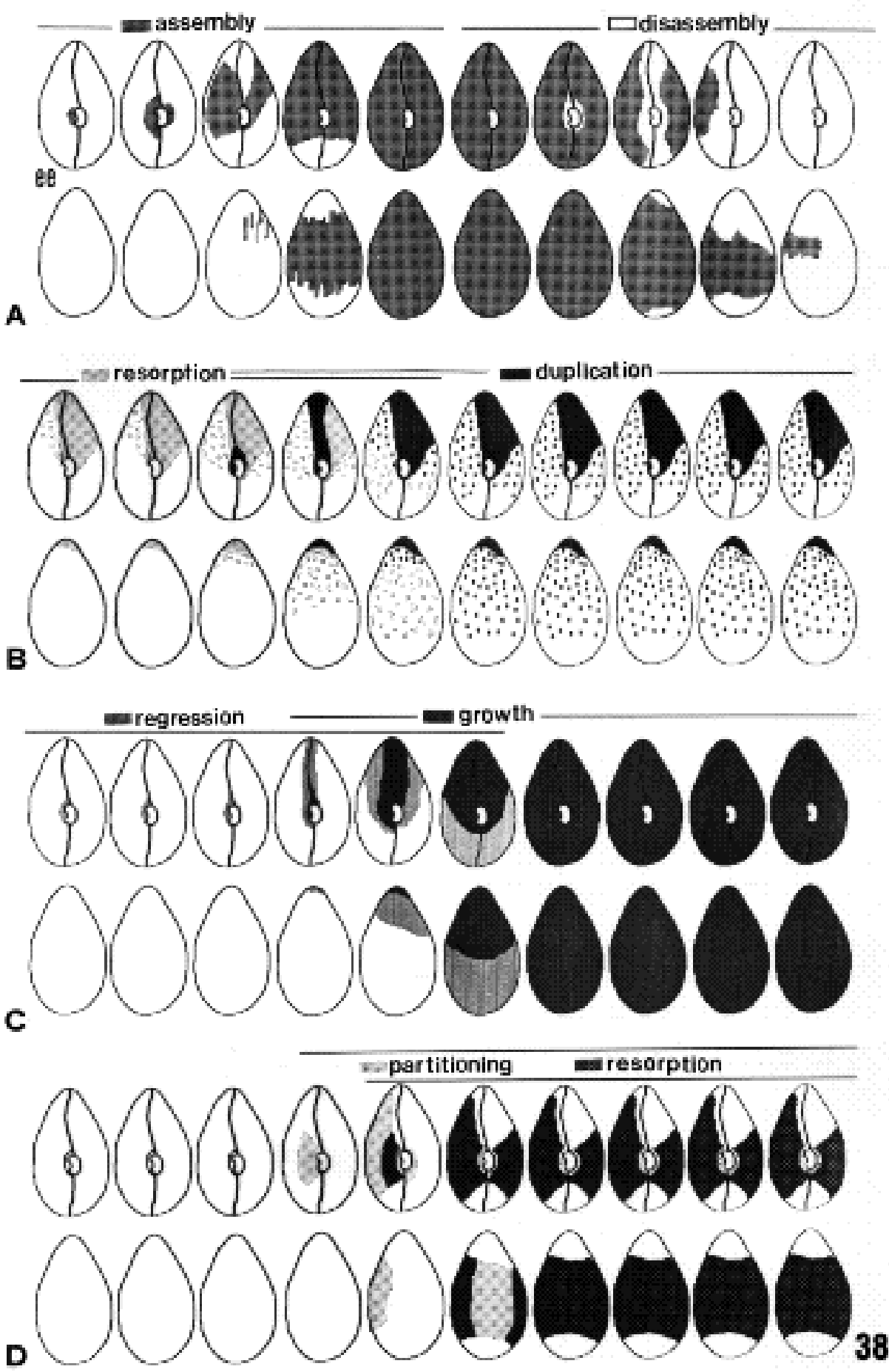

Fig. 38. Schematic diagram of the progression of the different morphogenetic waves over the exconjugant cells. Shadings on the scheme indicate the regions of the cortex already invaded by each remodelling wave at each stage. Each series of schemes represents the progression from the stage of early exconjugant (ee). The upper drawing corresponds to the ventral surface of the cell and the lower one corresponds to the dorsal surface. (A) Cytospindle. (B) Basal bodies. When cells separate basal body resorption has already occurred in the zone marked on the first two schemes of this series. (C) Ciliary rootlets. Shadings on the first two schemes indicate the zone appearing disorganized when conjugating cells separate, where basal bodies are disarranged and lack ciliary rootlets. (D) Outer lattice and epiplasm. After conjugation cortical units around the oral opening are not well defined. Outer lattice meshes and epiplasm scales in this zone are rebuilt in the exconjugant. Partitioning refers to formation of new septa of outer lattice between some of the preexisting ones. Resorption means degradation of some of the preexisting partitions of outer lattice. al., 1989). It seems to ensure the correct arrangement of remodelled structures in the cortex. The cytospindle appears before ciliary rootlets regress and basal bodies duplicate. When new fibres and new basal bodies are formed the cytospindle disassembles. Thus, the cytospindle appears to substitute for the scaffold formed by ciliary rootlets while they regress and regrow.

This study reveals that a complicated morphogenetic process takes place during conjugation of Paramecium, a process that does not involve cytokinesis. Substantial differences have been detected between the developmental mechanisms used by this ciliate during asexual and sexual reproduction processes.

During cell division, both the oral apparatus and cortical units are duplicated in order to form two complete organisms. Basal body duplication during asexual reproduction is a totally conservative process, since all preexisting basal bodies are retained. Although the total number of basal bodies is duplicated, not all the cortical units behave in the same way, since hyperduplicating and invariant territories exist. Outer lattice meshes are duplicated by elongation of the preexisting ones and posterior partitioning. 
Contrarily, during conjugation the old oral apparatus is resorbed and a new one is formed independently of the old one. Our observations reveal that the cells become deeply dedifferentiated and that somatic cortical structures are renewed after conjugation. Basal bodies and the outer lattice, conserved during division, undergo a remodelling process during conjugation. Part of the preexisting elements are destroyed and others are newly formed in order to replace them.

Every 2-bb cortical unit in the exconjugant cell resorbs its anterior basal body. Such dedifferentiation has never been described in Paramecium. Basal body duplication occurs and the cell recovers the normal pattern of basal bodies. This process in exconjugant Paramecium displays two important differences compared to that occurring in dividing cells. First, it is not a conservative mechanism, since part of the preexisting basal bodies are resorbed. Second, the anterior region of the cell, described by Iftode et al. (1989) as an invariant territory during division, undergoes basal body resorption and duplication during conjugation.

In both cell processes, conjugation and cell division, all the cortical structures are globally reorganized following morphogenetic waves that extend over the cell surface. During binary fission, there are two partially autonomous morphogenetic entities, with two independent morphogenetic epicentres, corresponding to the oral systems of the anterior and posterior division products respectively. The fission furrow acts as a region of discontinuity and a secondary inductive zone (Iftode et al., 1989; Delgado et al., 1990).

Unlike dividing cells, the exconjugant organism is a single morphogenetic unit. At the whole cell level, all the remodelling waves spread from the oral region to the left and right sides of the cell. The oral apparatus therefore may be considered as the global morphogenetic epicentre during conjugation. Nevertheless, at the ciliary row level, it is observed that the remodelling of basal bodies and ciliary rootlets starts from the anterior suture line (always beginning at the rows closest to the buccal opening). From that point, remodelling continues posteriorly along the rows. Thus, the preoral suture acts as a secondary morphogenetic epicentre. An important morphogenetic role of the anterior suture of ciliates has previously been recognized (Tartar, 1967; Sonneborn, 1970b). Taking into account the basal body and ciliary rootlet remodelling waves in conjugating cells, the preoral suture is analogous to the fission furrow in dividing cells, which also acts as a secondary epicentre. In fact, with regard to basal body duplication and ciliary rootlet remodelling waves, an exconjugant cell is similar to the posterior product of the division, the preoral suture in the former playing the same role that the fission furrow in the latter.

Unlike basal body and ciliary rootlet remodelling, cytospindle formation and regression follow a bidirectional trajectory. The assembly proceeds from the centre to the ends of the rows and disassembly proceeds from the suture lines to the centre. Thus, although the cortex as a general structure is renewed when cells conjugate, waves of assembly and disassembly of different structures proceed in different temporal and spatial sequences. In addition, not all the remodelling waves affect every region of the cortex in the same way. We have seen that ciliary rootlet renewal occurs over the entire surface, whereas basal body resorption and duplication affect the 2-bb and the mixed field, but not the 1-bb field, and outer lattice remodelling affects only the mixed field. Thus, the structural heterogeneity of the cortex of Paramecium is maintained either by an unequal distribution of the morphogenetic signals over the cell surface or by different responses of the different cortical regions to the morphogenetic signals.

Despite those particular differences, morphogenetic waves have a common characteristic, they all begin to propagate from the oral apparatus, which seems to act as the integrator element of the morphogenetic process. The oral system seems to be the chief surface component of Para mecium, resorption of which is the first event of a major developmental process in this organism, involving both stomatogenesis and general cortical morphogenesis. The cortical cytoskeleton seems to behave like the oral system, in both division and conjugation. In division both systems are duplicated in close contact with the preexisting structures, and in conjugation both are renewed and regenerated.

Morphogenetic events seem to have two different manifestations in the cortex that could define how global cortical development in conjugation occurs: (a) degradation and neoformation of some cortical structures (ciliary rootlets, basal bodies, outer lattice), and (b) redistribution of preexisting material within the cortex (epiplasm, basal bodies).

The elaborated cortical reorganization reported here once more demonstrates the importance of the sexual process of conjugation in the life cycle of ciliates, which involves a general, nuclear and somatic renewal.

So far, renewal of the oral apparatus has been the only morphogenetic process described during conjugation of Paramecium (Ng and Mikami, 1981; Ng and Newman, 1984). On the basis of the control of stomatogenesis during sexual reproduction, $\mathrm{Ng}$ and Fujishima (1989) considered postsexual somatic development in Paramecium to be analogous to embryonic development in multicellular organisms. The early embryogenesis of multicellular organisms requires maternal information from the oocytes, as well as the information furnished by the early postzygotic nuclei. Likewise, stomatogenesis during conjugation of Parame cium depends on the germ nucleus and also involves both maternal and postzygotic information.

In hypotrichous ciliates, cortical reorganization during conjugation has long been studied (Jerka-Dziadosz and Janus, 1975; Shi, 1976; Tuffrau et al., 1976, 1981; Fleury and Fryd-Versavel, 1981; Zou and $\mathrm{Ng}, 1991)$. In this group of ciliates all or nearly all of the old ciliature is resorbed and replaced by a new set during conjugation. Sexual cortical development consists of two or three rounds of reorganization. The second round of cortical reorganization requires (like stomatogenesis in conjugating Paramecium) information from postzygotic and maternal nuclei. In view of this, $\mathrm{Ng}$ (1990) extends the embryological perspective of the sexual reproduction to hypotrichs. Thus, postsexual cortical development in both Paramecium and hypotrichs are considered to be parallel. The results reported here reinforce this concept, since they show that somatic reorganization in Paramecium, as in hypotrichs, extends to the 
entire cortex, i.e., a new soma is generated after fertilization.

This work was supported by grants from the Junta de Andalucía and DGICYT (No. PB91/0621). We would like to thank A. Adoutte, J. Beisson, J. C. Clerot, A. Fleury, G. Keryer, T. E. Kreis, G. Piperno, P. N. Rao and L. Sperling for generous gifts of antibodies. We thank P. Delgado for critical reading of the manuscript.

\section{REFERENCES}

Adoutte, A., Delgado, P., Fleury, A., Levilliers, N., Laine, M. C., Marty, M. C., Boisvieux-Ulrich, E. and Sandoz, D. (1991). Microtubule diversity in ciliated cells: evidence for its generation by posttranslational modification in axonemes of Paramecium and quail oviduct cells. Biol. Cell 71, 227-245.

Beisson, J. and Sonneborn, T. M. (1965). Cytoplasmic inheritance of the organization of the cell cortex in Paramecium aurelia. Proc. Natl. Acad. Sci. USA 53, 275-282.

Cohen, J., Adoutte, A., Grandchamp, S., Houdebine, L. M. and Beisson, J. (1982). Immunochemical study of microtubular structures throughout the cell cycle of Paramecium.Biol. Cell 44, 35-44.

Cohen, J., Garreau de Loubresse, N., Klotz, C., Ruiz, F., Bordes, N., Sandoz, D., Bornens, M. and Beisson, J. (1987). Organization and dynamics of cortical fibrous network of Paramecium: the outer lattice. Cell Mot. Cytoskel. 7, 315-324.

Davis, F. M., Tsai, T. Y., Fowler, S. K. and Rao, P. N. (1983). Monoclonal antibodies to mitotic cells. Proc. Natl. Acad. Sci. USA 80, 2926-2930.

Delgado, P., Romero, M. R. and Torres, A. (1990). Microtubular systems of Paramecium in division: pattern of cytospindle assembly. J. Protozool. 37, 182-186.

Dippell, R. V. (1964). Perpetuation of cortical structure and pattern in Paramecium aurelia.Proc. 11th Int. Congr. Cell Biol. 1964, 16-17.

Dippell, R. V. (1965). Reproduction of surface structure in Paramecium. In Progress in Protozool.2nd. Int. Conf. on Protozoology. London.

Dippell, R. V. (1968). The development of basal bodies in Paramecium. Proc. Natl. Acad. Sci. USA 61, 461-468.

Ehret, C. F. and MacArdle, E. W. (1974). The structure of Paramecium as viewed from its constituent levels of organization. In Paramecium, $A$ Current Survey (ed. Wagtendonk), pp. 263-337. Amsterdam: Elsevier.

Fernández-Galiano, D. (1978). Le comportement des cinétodesmes pendant la division de Paramecium caudatum. Protistologica 14, 291294.

Fleury, A. and Fryd-Versavel, G. (1981). Données nouvelles sur quelques processus morphogénétiques chez les hypotriches, notamment dans le genre Euplotes: leur contribution à l'approche evolutionniste du problème de la régulation de l'activité morphogénétique chez les ciliés. $J$. Protozool. 28, 283-291.

Grandchamp, S. and Beisson, J. (1981). Positional control of nuclear differentiation in Paramecium. Dev. Biol. 81, 336-341.

Iftode, F., Cohen, J., Ruiz, F., Torres-Rueda, A., Chen-Shan, L., Adoutte, A. and Beisson, J. (1989). Development of surface pattern during division in Paramecium. Development 105, 191-211.

Jerka-Dziadosz, M. and Janus, I. (1975). Discontinuity of cortical pattern during total conjugation of a hypotrich ciliate Paraurostyla weisei.Acta Protozool. 8, 309-333.

Kaneda, M. and Hanson, L. (1974). Growth patterns and morphogenetic events in the cell cycle of Parameciumaurelia. In Paramecium (ed. Van Wagtendong), pp. 219-262. Berlin: Springer-Verlag.

Kreis, T. E. (1987). Microtubules containing detyrosinated tubulin are less dynamic. EMBO J. 6, 2597-2606.

Kwok, F. W. K. and Ng, S. F. (1989). 5-azacytidine affects the programming of expression of the somatic nucleus of Paramecium. Development 105, 559-568.

Ng, S. F. (1986). The somatic function of the micronucleus of ciliated protozoa. Progr. Protistol. 1, 215-286.

Ng, S. F.(1990). Embryological perspective of sexual somatic development in ciliated protozoa: implications on immortality, sexual reproduction and inheritance of acquired characters. Phil. Trans. R. Soc. Lond. B. 329, $287-$ 305.

Ng, S. F. and Fujishima, M. (1989). Control of development of the oral apparatus of Paramecium during sexual reproduction: An embryological perspective. Dev. Biol. 134, 317-326.

Ng, S. F. and Mikami, K. (1981). Morphogenetic role of the germ nucleus in Parameciun tetraurelia. Protistologica 17, 497-509.

Ng, S. F. and Newman, A. (1984). The role of the micronucleus in stomatogenesis in sexual reproduction of Paramecium tetraurelia: Micronuclear and stomatogenic events. Protistologica T.XX(1), 43-64.

Parducz, B. (1962). On a new concept of cortical organization in Paramecium. Acta Biol. Hung. 13, 299-322.

Piperno, G. and Fuller, M. T. (1985). Monoclonal antibodies specific for an acetylated form of $\alpha$-tubulin recognize the antigen in cilia and flagella from a variety of organisms. J. Cell Biol. 101, 2085-2094.

Schliwa, M. and Van Blerkom, J. (1981). Structural interactions of cytoskeletal components. J. Cell Biol. 90, 222-235.

Shi, X. B. (1976). Studies on conjugation in Stylonychia mytilus. II. Morphogenesis of argentophilic system. Acta Zool. Sinica 22, 71-83.

Sonneborn, T. M. (1963). Does preformed cell structure play an essential role in cell heredity? In The Nature of Biological Diversity (ed. J. M. Allen), pp. 165-221. New York: McGraw Hill Publishing.

Sonneborn, T. M. (1970a). Methods in Paramecium research. In Methods in Cell Physiology (ed. Prescott, D. M.), pp. 241-339. New York: Academic Press.

Sonneborn, T. M. (1970b). Gene action in development. Proc. Roy. Soc. Lond. B 176, 347-366.

Sonneborn, T. M. (1975). Positional information and nearest neighbour interactions in relation to spatial patterns in ciliates. Ann. Biol. XIV, 565584.

Sperling, L., Keryer, G., Ruiz, F. and Beisson, J. (1991). Cortical morphogenesis in Paramecium : A transcellular wave of protein phosphorylation involved in ciliary rootlet disassembly. Dev. Biol. 148, 205-218.

Sundararaman, V. and Hanson, E. D. (1976). Longitudinal microtubules and their functions during asexual reproduction in Paramecium tetraurelia. J. Genet. Res. Cam. 27, 205-211.

Tam, L. W. and Ng, S. F. (1986). The role of the micronucleus in stomatogenesis in sexual reproduction of Paramecium tetraurelia: laser microbean irradiation of the micronucleus. J. Cell Sci. 86, 287-303.

Tartar, V. (1954). Anomalies in regeneration of Paramecium.J. Protozool. 1, 11-17.

Tartar, V. (1967). Morphogenesis in protozoa. In Research in Protozoology, Vol. 2 (ed. T. T. Chen), pp. 1-105. New York: Pergamon Press.

Tuffrau, M., Fryd-Versavel, G. and Tuffrau, H. (1981). La réorganisation infraciliaire au cours de la conjugaison chez Stylonychia mytilus. Protistologica 17, 387-396.

Tuffrau, M., Tuffrau, H. and Génermont, J. (1976). La réorganisation infraciliaire au cours de la conjugaison et l'origine du primordium buccal dans le genre Euplotes. J. Protozool. 23, 517-523.

Von Gelei, G. (1937). Ein neues Fibrillensystem im Ectoplasma von Paramecium; zugleich ein Vergleich zwischen dem neuen und dem alten gittersystem. Arch. Protistenk. 89, 299-322.

Zou, S. F. and Ng, S. F. (1991). Commitment to the first cortical reorganization during conjugation in Stylonychia mytilus: an argument for homology with cortical development during binary fission. $J$. Protozool. 38, 192-200.

(Accepted 24 November 1992) 